\title{
A truck-mounted mobile screen for photodigital estimation of whole plant leaf area
}

\author{
R.J. ANSLEY, D.L. PRICE, B.K. LAWRENCE, AND P.W. JACOBY
}

\begin{abstract}
A large, truck-mounted screen was constructed to aid in measurement of total leaf area of individual honey mesquite (Prosopis glandulosa Torr.) trees. The screen, which measured $4.6 \mathrm{~m} \times 6.2 \mathrm{~m}$, was constructed with a white tarp supported by a PVC and steel frame, and mounted via steel brackets to one side of a crew-cab truck. To alleviate problems with wind and to facilitate transport, the tarp was attached only at the top of the frame and could be raised and lowered as required. The screen could be transported in the unassembled condition using a standard truck transport frame. The assembled screen was used in a natural rangeland setting to provide a consistent background for photography of individual trees. A 35-mm camera and a portable VCR recorder were used to obtain 2 dimensional images of the tree canopy, which were then digitized. These values were related to whole plant leaf area by harvesting entire trees. A crew of 4 was required to assemble the screen and photograph about 35 trees within 4 hours.
\end{abstract}

Key Words: honey mesquite (Prosopis glandulosa), plant water use, biomass, canopy architecture

Water relations studies of woody plants have concentrated on measurement of activity at the micro (leaf or subleaf) level of resolution (Thomas and Sosebee 1978, Nilsen et al. 1981). Increasingly there is a need for determination of water use at the macro (whole plant) level since leaf activity can vary substantially within a tree canopy because of shading (Caldwell et al. 1986). Estimation of total green mass is closely correlated with total transpiration activity (Larcher 1975).

Most leaf area estimates of woody plants involve either destructive sampling of the entire canopy or subsampling portions of the canopy (Brown 1976, Waring et al. 1977, Ganskopp and Miller 1986) or development of geometric volume to area relationships (Ludwig et al. 1975, Murray and Jacobson 1982, MacDonald and Forslund 1986). While accurate, these methods are time consuming and limit information gained generally to 1 point in time, thus

Authors are postdoctoral research associate, Texas Agricultural Experiment Station, Vernon; instructor, Range Science Dept., Texas A\&M University, College Station; and technican and professor, Texas Agricultural Experiment Station, Vernon.

Research was funded in part by University Lands-Surface Interests, Univ. Texas System, Midland; E. Paul and Helen Buck Waggoner Foundation, Vernon, Texas.

This article is being published as technical article TA-23455 from the Texas Agricultural Experiment Station.

Manuscript accepted 29 February 1988.
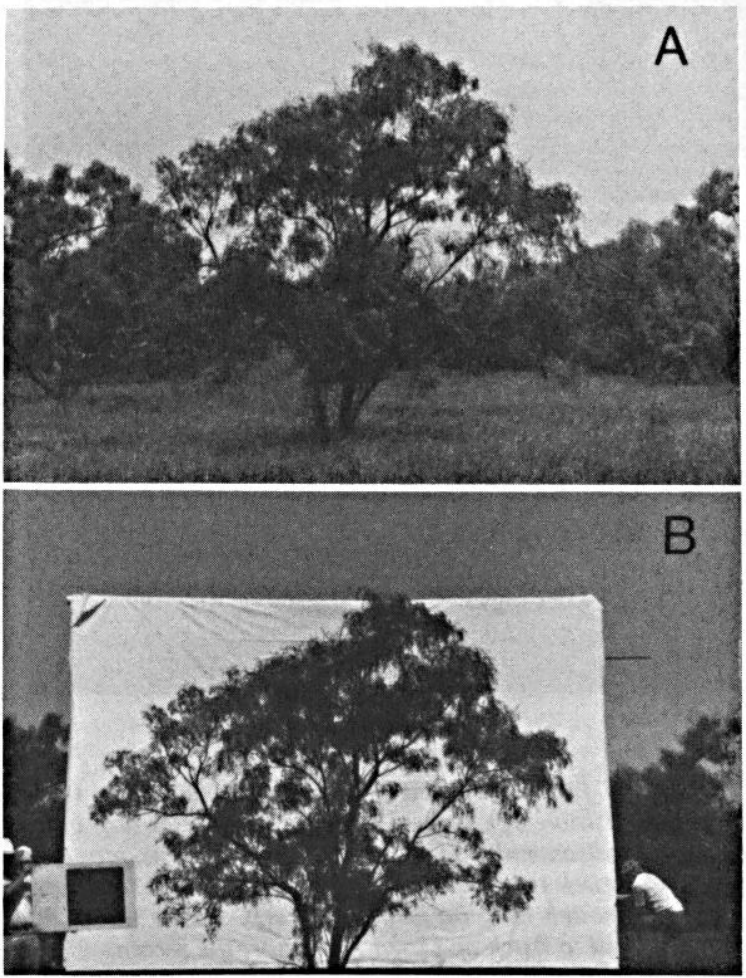

Fig. 1. Honey mesquite tree in a natural set ting $(A)$, and same tree visually separated from background vegetation by mobile screen (B). Black 0.25 $\mathrm{m}^{2}$ square on lower left is used for size reference during image digitizing process.

precluding measurement of seasonal or yearly changes in total leaf area.

Photography at close range would appear to be a quick and efficient method of estimating total leaf area of individual plants. 
dimensional images of trees were used to estimate whole plant leaf area.

\section{Methods and Materials}

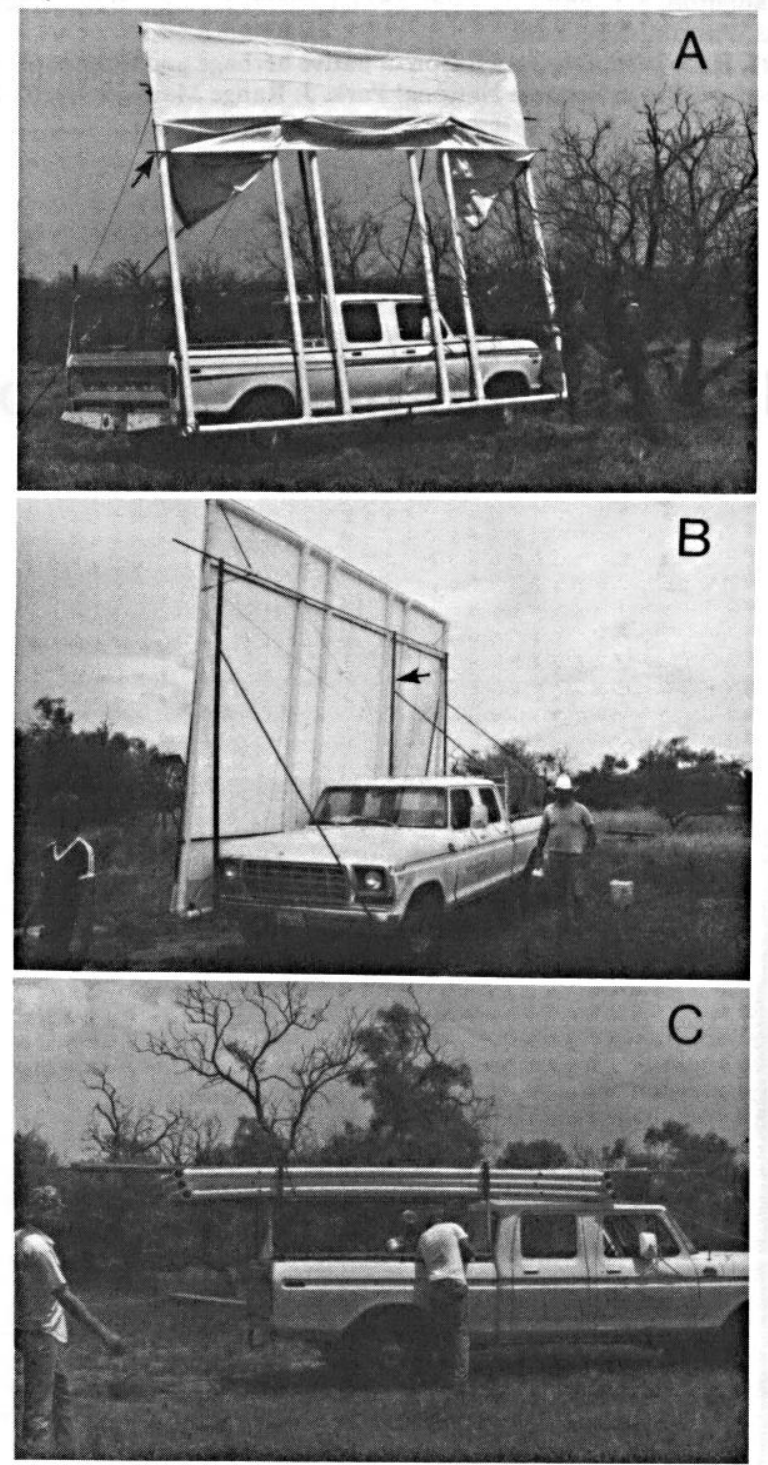

Fig. 2. White PVC frame mounted in an upright position on truck with tarp in raised position $(A)$, reverse angle of frame with tarp in lowered position (B) and disassembled frame with 3 PVC sections, pipe and angle iron placed on truck transport frame $(C)$. Arrow in $(A)$ indicates steel pipe inserted through loop on bottom of tarp. Arrow in $(B)$ refers to $M$-frame attached to truck and used to support the screen.

Usually this method involves positioning a screen or grid behind the plant to provide scale (Carbon et al. 1979, Koike 1985). While most studies involve use of small screens for plants less than $2 \mathrm{~m}$ high, honey mesquite (Prosopis glandulosa Torr.) can achieve heights greater than $5 \mathrm{~m}$. Providing a portable screen of sufficient size to measure area of individual mesquite trees occurring in a natural setting was a problem encountered in our study (Fig. 1). The objective of this technical note is to describe construction and utility of a large, truck-mounted screen for photographing individual trees in the field, and to outline a method whereby digitized 2

\section{Screen Construction}

Three $2 \mathrm{~m} \times 4.6-\mathrm{m}$ rectangles, each constructed of $8 \mathrm{~cm}$ diameter polyvinyl chloride (PVC) tubing, were adjoined with $0.5-\mathrm{m}$ sections of $8 \mathrm{~cm}$ diameter PVC tubing and PVC coupling joints to form the large frame $(4.6 \mathrm{~m} \times 6.2 \mathrm{~m})$ as shown in Figure 2. Two 2.5 $\mathrm{cm}$ diameter $\times 6.5$-m steel pipes were inserted as crossbars through holes in the PVC and fixed in position with pipe nuts on threaded ends. The pipes served to secure the 3 PVC sections together and, although they added substantially to the weight of the frame, were critical to maintenance of screen stability during high winds.

A $4.6 \mathrm{~m} \times 6.2-\mathrm{m}$ white reinforced truck tarp (weight $13.6 \mathrm{~kg}$ ) was attached via metal grommets located on the tarp edge to protruding bolts which were premounted at $0.3-\mathrm{m}$ intervals along the top (6.2 m length) of the PVC frame. Only the top of the tarp was attached directly to the frame. A $7 \mathrm{~m}$ long $\times 2.5 \mathrm{~cm}$ diameter steel pipe was inserted through a presewn loop on the bottom edge of the tarp (Fig. 2A). The inserted pipe facilitated raising and lowering the tarp and reduced tarp fluttering caused by wind when in the lowered position. Two ropes attached to grommets located on the bottom edge of the tarp and looped over the top crossbar pipe served to raise and lower the tarp. The tarp and PVC frame together were referred to as the screen.

\section{Truck Mounting}

The screen was supported $0.5 \mathrm{~m}$ above the ground by 3 removable "L" shaped brackets made from $2.5 \mathrm{~cm}$ diameter pipe and extended through $3 \mathrm{~cm}$ diameter pipe sections which were welded

Table 1. Cost of items required to construct photographic screen and screen mount for a pickup truck in 1986. Measurements are expressed in English units in accordance with common usage by the construction industry. Metric units are in parentheses.

\begin{tabular}{lccc}
\hline \hline Component & Supply Item & $\begin{array}{c}\text { Quantity } \\
\text { (Length or } \\
\text { \# units) }\end{array} \quad$ Cost \\
\hline
\end{tabular}

\section{Screen:}

(a) Frame
$3.0^{\prime \prime}(7.6 \mathrm{~cm})$ class $160 \mathrm{PVC}$ pipe
3.0" PVC "T" and "L" joints
$1.0^{\prime \prime}(2.5 \mathrm{~cm})$ steel pipe
Rubber straps
Hardware (nuts, bolts, washers)

\begin{tabular}{lr}
$37 \mathrm{~m}$ & 80.00 \\
12 & 25.00 \\
$16 \mathrm{~m}$ & 35.00 \\
10 & 10.00 \\
& 5.00 \\
\cline { 2 - 2 } Subtotal & 155.00 \\
& \\
1 & 150.00 \\
$8 \mathrm{~m}$ & 17.00 \\
& \\
& 15.00 \\
\hline Subtotal & 182.00
\end{tabular}

Truck ${ }^{1}$ :

(a) M-frame
$20 \times 15 \mathrm{ft}(6.2 \times 4.6 \mathrm{~m})$ custom tarp
$1^{\prime \prime}(2.5 \mathrm{~cm})$ pipe

Hardware and heavy gauge rope

$10 \mathrm{~m}$

$8 \mathrm{~m}$

$10 \mathrm{~m}$

$1.5^{\prime \prime}(3.8 \mathrm{~cm})$ square tubing

$1.0^{\prime \prime}(2.5 \mathrm{~cm})$ angle iron

(b) Brackets $1.0^{\prime \prime}$ black pipe

1.0 " black pipe "L" brackets

Hardware

\section{Subtotal}

12.00

16.00

10.00

$3 \mathrm{~m}$

38.00

3 each

10.00

$\quad 12.00$

Subtotal $\quad \frac{5.00}{27.00}$

TOTAL $\quad 402.00$

'Does not include load transport frame on truck bed. 

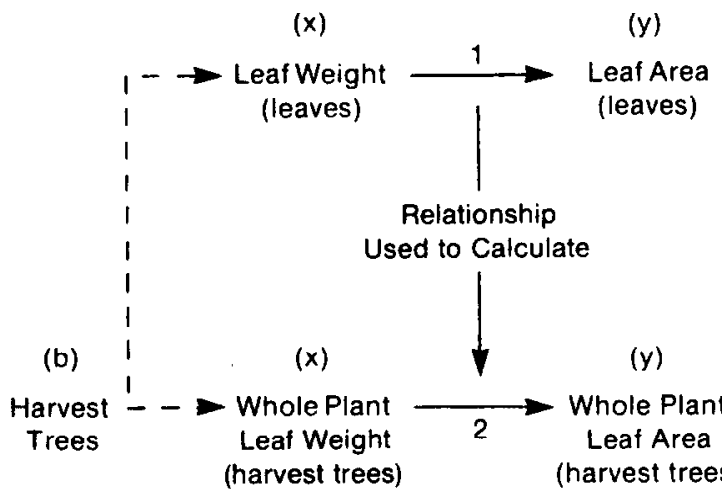

(y)

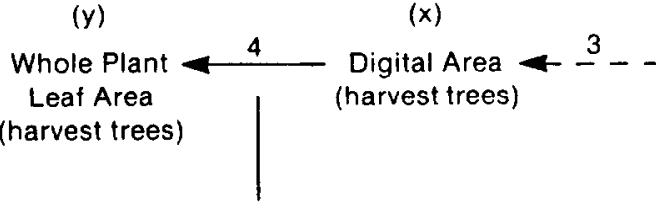

(x)

(a)

Photograph

(harvest trees)

Fig. 3. Schematic illustration of procedure to estimate whole plant leaf area from digitized 2 dimensional images of the tree. Letters a and b indicate data obtained from the field. Numbers $1-5$ indicate sequential steps in the procedure following field dat a collection. Letters $x$ and $y$ indicate independent and dependent variables during development of a predictive equation at a particular step. Dashed lines indicate transition of field-obtained data into various predictive equations. Salid lines indicate transition from one non-field step to another. Left-hand box illustrates 3 sampling resolution levels of the entire procedure.

to the truck frame (Fig. 2A). The brackets were held in place with bolts. A large M-shaped frame made of 3 vertically oriented square pipes connected to a $1.5 \mathrm{~cm}$ diameter horizontal pipe was attached to the truck load transport frame and front bumper on the passenger side of the truck. The $\mathrm{M}$-frame provided upright back support for the screen (Fig. 2B). Three sections of angle iron attached to the M-frame provided further support. Cost of materials for the screen and truck mount was $\$ 402$ (Table 1). The most expensive item was the custom-made tarp.

The screen was assembled in a horizontal position on the ground with tarp attached to the ground side of the PVC. For mounting on the truck, the bottom end of the frame was lifted on to the brackets, then the entire assembly was lifted to a vertical position against the $M$ frame. Four crewpersons were required to lift the screen. The bottom of the screen was far enough away from the truck body to permit turning of the front tires.

\section{Data Collection/Photography}

A minimum crew of 4 was required to obtain data using the mobile screen. Two were required to raise and lower the tarp and hold the bottom of the tarp taut during photography by stepping on the tarp pipe and by using rubber straps. The third crewperson operated photographic equipment and the fourth positioned a $0.25-\mathrm{m}^{2}$ reference square at each tree (Fig. 1B). We used a crew of 5 because we were assessing 2 methods of imaging whole tree leaf area: 1 using a standard $35 \mathrm{~mm}$ camera and the second using a video cassete recorder. A Delta T (Decagon, Inc., Pullman, WA) video digitizer was used to digitize the images from standard $8 \times 10$ black-and-white photographs. To verify our results entire trees were harvested and total leaf biomass was weighed. Leaf weight to leaf area linear regressions were determined from small samples and were used to estimate whole tree leaf area of the harvested trees. Values obtained digitally from 2 dimensional images of the tree canopies were then compared to harvest values of whole tree leaf area.

\section{Discussion}

\section{Logistical Considerations/Screen Requirements}

We estimated whole plant leaf area of mesquite trees which had 1 to 3 basal stems and were 3 to $4 \mathrm{~m}$ high by 4 to $6 \mathrm{~m}$ wide. The trees were too tall for us to obtain top-view images of individual canopies at the desired resolution level. Our needs therefore were to construct a screen at least $4 \mathrm{~m}$ high by $6 \mathrm{~m}$ wide to accommodate photographing side views of the canopies. Portability of the screen was required because we intended to photograph 30-40 trees, each 50-100 $\mathrm{m}$ apart, within a brief period of time. Transporting by hand was impractical because of screen bulk and the large crew (6-8) required. Other requirements were that the screen be easily mounted in the unassembled condition on a pickup truck for highway transport. Assembly of the screen once in the field had to be quick and relatively easy.

All of these objectives were accomplished with the design of the screen. When attached to the truck, the screen was easily maneuvered into position behind target trees. The ability to raise and lower the tarp enabled us to use the screen in winds as high as 35 $\mathrm{kmph}$. The screen was in the raised position during transport from tree to tree then lowered briefly for the photography. We were able to photograph all trees within a 4-hr interval. Screen assembly time was about $30 \mathrm{~min}$. Twenty minutes were needed to disassemble and load components on to the truck. PVC, pipe, and angle iron were loaded on the truck transport frame (Fig. 2C). Hardware, tarp and reference square were carried in the truck bed. 


\section{Photoimaging and Digital Analysis}

Two dimensional side-view images of the trees were obtained from fixed camera points and fixed screen positions throughout the season. The procedure whereby digitized images of the tree were used to estimate whole tree leaf area is illustrated schematically in Figure 3: Following photographing in the field (a) some trees were harvested (b). A small amount of leaves from the harvested trees was used to develop leaf weight to leaf area linear regressions for each sample date (1). These regressions were used to estimate whole tree leaf area of the harvest trees from whole tree leaf weight (2). Photographs of the harvest as well as additional non-harvest trees were digitized (3). The black $0.25-\mathrm{m}^{2}$ reference square on each photograph (Fig. 1B) was used to calibrate the digitizer so that digital values were expressed on a $\mathrm{m}^{2}$ basis. Digital values from images of the harvest trees were compared to actual whole tree leaf area (4) and predictive equations were determined to estimate whole tree leaf area of non-harvest trees based on digitized images (5). An example of step 4 as illustrated in Figure 3 is shown for a single sample date in Figure 4. Relationships determined in step 4 as well as step 1 (Fig. 3) varied with sample date and

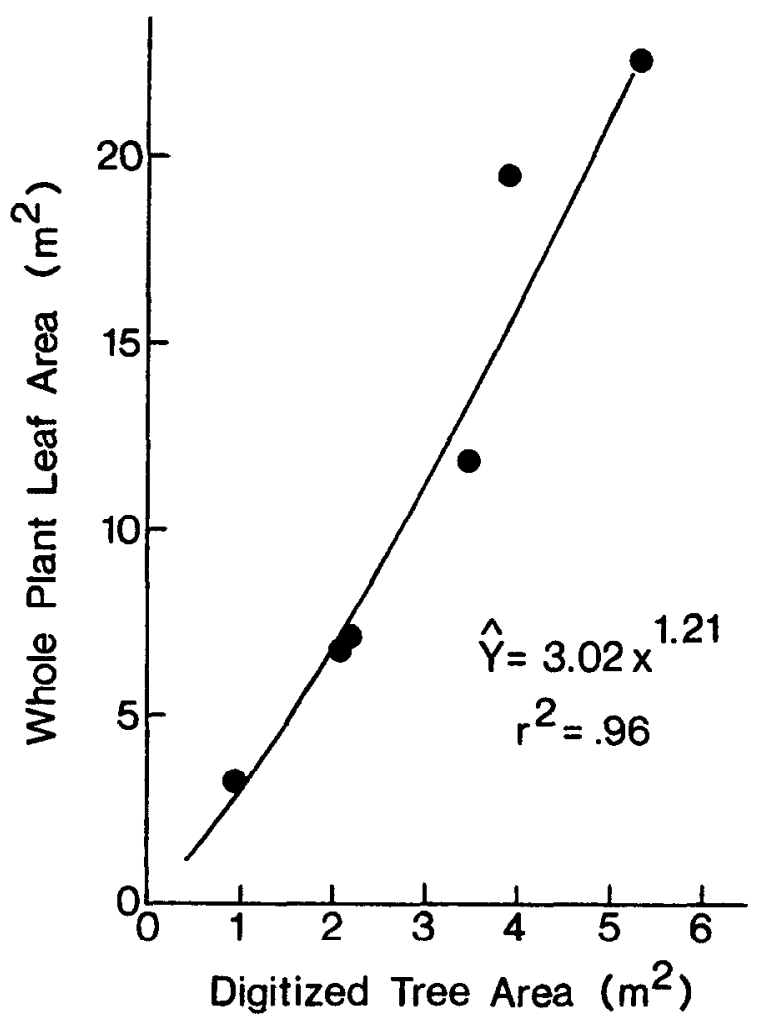

Fig. 4. Regression between area obtained from digitation of 2 dimensional black and white images of the tree ( $x$ axis) and whole plant leaf area obtained from actual harvest of 6 honey mesquite trees (y axis) which were photographed and harvested June $11,1987$.

will be discussed in a future paper. Digitized images have been used to provide quantitative information regarding woody plant anatomy (Yanosky and Robinove 1986, Goelz and Burk 1987). The primary advantage of our method was that seasonal changes in canopy area of the same individuals could be measured without destructively harvesting tissue as indicated by resolution level $\mathrm{C}$ in Figure 3.

\section{Disadvantages}

While the screen was judged a success for our research needs, it was not without problems. Following is a list of some of the major disadvantages of this technique: (1) Tree density-Use of the screen was limited to areas where a truck could be driven near a tree. Our site was somewhat of a mesquite savanna, so clearing of brush and unwanted trees was minimal; (2) Wind-Screen stability was adequate even in high winds. However, when wind blew directly into the screen, shading occurred on the screen from the tarp pressing into the frame and this affected digitation of the photographs; (3) Crew-While truck mobility reduced crew size, at least 4 crewpersons were required to operate the screen; (4) Screen Size-We were limited to photographing trees less than $4 \mathrm{~m}$ high and $6 \mathrm{~m}$ wide. Many virgin mesquite were taller and many resprout mesquite wider, but we felt a larger screen would not be stable enough; (5) Sun Angle - Due to shading caused by low sun angle in mornings and evenings, we were limited to photographing between 1000 and 1400 hours. On overcast days time limit was not a problem; (6) Leaf overlap-An inherent problem of using a 2 dimensional image to estimate a 3 dimensional quantity (whole plant leaf area) was that more leaf overlap occurred on photographs of large trees with deep canopies. This caused a slightly curvilinear relationship between digitized values and actual harvest values of whole plant leaf area (Fig. 4).

\section{Literature Cited}

Brown, J.K. 1976. Estimating shrub biomass from basal stem diameters. Can. J. Forest. Res. 6:153-158.

Caldwell, M.M., H.-P. Meister, J.D. Tenhunen, and O.L. Lange. 1986. Canopy structure, light microclimate and leaf gas exchange of Quercus coccifera L. in a Portuguese macchia: measurements in different canopy layers and simulation with a canopy model. Trees 1:25-41.

Carbon, B.A., G.A. Bartle and A.M. Murray. 1979. A method for visual estimation of leaf area. Forest Sci. 25:53-58.

Ganskopp, D., and R. Miller. 1986. Estimating leaf area of big sagebrush from measurement of sapwood. J. Range Manage. 39:338-340.

Goelz, J.C.G., and T.E. Burk. 1987. Testing a photographic method for measuring stem cross-sections. Forest Sci. 33:784-789.

Koike, F. 1985. Reconstruction of two-dimensional tree and forest canopy profiles using photographs. J. Applied Ecology 22:921-929.

Lurcher, W.1975 Physiological plant ecology. Springer-Verlag, New York. p. $180-181$.

Ludwig, J.A., J.F. Reynolds, and P.D. Whitson. 1975. Size-biomass relationships of several Chihuahuan desert shrubs. Amer. Midl. Natur. 94:451-461.

MacDonald, G.B., and R.R. Forslund. 1986. Application of a geometric volume equation to species with different bole forms. Can. J. Forest. Res. 16:311-314.

Murray, R.B., and M.Q. Jacobson. 1982. An evaluation of dimension analysis for predicting shrub biomass. J. Range Manage. 35:451-454.

Nilsen, E.T., P.W. Rundel, and M.R. Sharifl. 1981. Summer water relations of the desert phreatophyte Prosopis glandulosa in the Sonoran desert of southern California. Oecolgia 50:271-276.

Thomas, G.W., and R.E. Sosebee. 1978. Water relations of honey mesquite - a facultative phreatophyte. Proc. Ist Int. Rangeland Congr., Denver, Colo. p. 414-418.

Waring, R.H., H.L. Ghol,, C.C. Grier, and M.L. Plummer. 1977. Evaluating stem conducting tissue as an estimator of leaf area in 4 woody angiosperms. Can. J. Bot. 55:1474-1477.

Yanosky, T.M., and C.J. Robinove. 1986. Digital image measurement of the area and anatomical structure of tree rings. Can. J. Bot. 64:2896-2902. 